\title{
HUBUNGAN DUKUNGAN KELUARGA DENGAN KEPATUHAN MINUM OBAT PADA PASIEN SKIZOPRENIA DI POLI KLINIK RSJ PROF. DR. MUHAMMAD ILDREM MEDAN
}

\author{
Surita Br Ginting \\ Jurusan Kebidanan Poltekkes Kemenkes Medan
}

\begin{abstract}
Abstrak
Skizoprenia adalah suatu gangguan jiwa yang ditandai dengan adanya penyimpangan yang sangat dasar dan adanya perbedaan pikiran, disertai adanya ekspresi emosi yang tidak wajar. Skizoprenia sering ditemukan pada masyarakat dan dapat dialami oleh setiap manusia. Dukungan keluarga sangat dibutuhkan dalam kepatuhan pengobatan dan minum obat. Jika dukungan keluarga baik dalam pengobatan dan pemberian obat secara rutin pada pasien skizoprenia maka patuh dalam minum obat. Tujuan penelitian ini untuk mengetahui hubungan dukungan keluarga dengan kepatuhan minum obat pada pasien di rumah. Penelitian ini merupakan penelitian analitik dengan pendekatan cross sectional untuk mengetahui hubungan dukungan keluarga dalam kepatuhan mengkonsumsi obat pada pasien skizoprenia di poli klinik RSJ M. Ildrem, Adapun jumlah sampel penelitian ini sebanyak 66 sampel keluarga pasien skizoprenia. Instrumen penelitian ini berupa kuesioner dan data rekam medis. Pengambilan sampel dalam penelitian ini dengan menggunakan teknik accidental sampling, dan purposive. Hasil penelitian yang didapat dari tingkat kepatuhan mengkonsumsi obat pada pasien skizoprenia setiap dukungan keluarga berdasarkan emosional, patuh 9 responden (20\%), yang tidak patuh 3 responde (7\%),instrumental yang patuh 1 responden (2,27\%), yang tidak patuh 4 responden $(9.0 \%)$, informasi yang patuh 10 responden $(23 \%)$, yang tidak patuh 7 responden $(16 \%)$, penghargaan 10 responden $(22 \%)$ dan semuanya patuh.
\end{abstract}

Kata kunci : Dukungan keluarga, kepatuhan dan skizoprenia

\section{A. Pendahuluan}

Gangguan jiwa merupakan salah satu masalah kesehatan utama di negara-negara maju. Gangguan jiwa adalah gangguan pada fungsi mental, yang meliputi emosi, pikiran, prilaku, motivasi gaya tilik diri dan persepsi yang menyebabkan penurunan semua fungsi kejiwaan terutama minat dan motivasi sehingga mengganggu seseorang dalam proses hidup dimasyarakat (Nasir dan Muhith, 2011). Menurut Hawari, 2012, menyatakan bahwa banyak orang menganggap gangguan jiwa merupakan penyakit yang tidak dapat diobati. Keluarga adalah bagian penting dalam proses pengobatan pasien jiwa. Dukungan keluarga sangat diperlukan oleh penderita gangguan jiwa dalam memotivasi mereka selama perawatan dan pengobatan (Yosep, 2009).

Dukungan keluarga merupakan sikap dan tindakan maupun penerimaan keluarga terhadap penderita sakit, serta memberi fungsi dan peran keluarga sebagai sistem pendukung dalam memberikan pertolongan dan bantuan bagi anggotanya yang menderita sakit serta suatu proses yang terjadi sepanjang kehidupan. Sifat dan jenis dukungan sosial berbeda-beda dalam berbagai siklus kehidupan. Dukungan sosial keluarga membuat keluarga mampu berfungsi untuk meningkatkan kesehatan dan adaptasi keluarga. selalu siap memberikan pertolongan dan bantuan melalui dukungan yang mencakup dukungan emosional, instrumental, informasi dan dukungan penghargaan. (Freedmen, 2010) Menurut Potter dan Perry (2009), dukungan keluarga merupakan bentuk pemberian dukungan terhadap anggota keluarga lain yang mengalami permasalahan, yaitu memberikan dukungan pemeliharaan, emosional untuk mencapai kesejahteraan anggota keluarga dan memenuhi kebutuhan psikososial. Menurut Friedman (1998) bentuk dukungan keluarga terdiri dari 4 macam dukungan yaitu : dukungan informasi, dukungan penghargaan, dukungan instrumental, dukungan emosional.

Beberapa penelitian menunjukkan ada pengaruh yang signifikan antara dukungan emosional, instrumental, informasi dan penghargaan dengan dukungan keluarga diantaranya, beberapa keluarga menunjukkan sikap memberikan dukungan terhadap penderita skizoprenia dan keluarga selalu memberikan apa yang dibutuhkan penderita seperti support penghargaan, perhatian sebagai pemberi bimbingan serta motivasi dorongan sekaligus memberikan fasilitas yang dibutuhkan penderita, memberikan penjelasan atau informasi kepada penderita bahwasanya kesehatan sangat penting untuk dirinya. Hal itu dikarenakan keluarga lebih mudah mengajak penderita untuk kontrol atau rutin berobat pada setiap waktu yang ditentukan dalam berobat. Setiap dukungan yang diberikan keluarga dalam perawatan penderita skizoprenia 
diharapkan ada pengaruh baginya dan dapat meningkatkan keinginan penderita untuk sembuh dan memperkuat penderita agar lebih patuh untuk berobat dan minum obat.

Kepatuhan adalah tingkat pasien melaksanakan cara pengobatan dan perilaku yang disarankan dokter atau oleh yang lainnya (Bart Smet, 1990). Keberhasilan perawatan di pasien khususnya konsumsi obat pasien menjadi sia-sia jika tidak ditunjang dukungan keluarga. Banyaknya pasien jiwa yang mengalami kekambuhan karena ketidak patuhan mengkonsumsi obat, adalah bagian penting dalam proses pengobatan pasien jiwa. Dukungan keluarga sangat diperlukan oleh penderita gangguan jiwa dalam memotivasi mereka selama perawatan dan pengobatan (Yosep, 2009). Hawari (2003) juga menambahkan perilaku kepatuhan pasien dalam mengkonsumsi obat lebih cenderung mengalami kekambuhan, selain itu Stuart dan Laraia (2005) manambahkan bahwa ketidak patuhan minum obat memiliki tingkat kekambuhan yang tinggi dengan gejala pasif yang menonjol atau parah.

WHO memperkirakan ada sekitar 450 juta orang di dunia mengalami gangguan jiwa. Pada masyarakat umum terdapat $0,2-0,8 \%$ penderita skizoprenia dan dari 120 juta penduduk di Negara Indonesia terdapat kira-kira 2.400.000 orang anak mengalami ganngguan jiwa (Maramis, 2004 dalam Carolina, 2008). Berdasarkan WHO (2009) memperkirakan 450 juta jiwa diseluruh dunia mengalami gangguan mental, sekitar $10 \%$ orang dewasa mengalami gangguan jiwa pada usia tertentu selama hidupnya. Usia ini biasanya terjadi pada dewasa muda antara usia 18-21 tahun. Menurut National Institute Of Mental Health gangguan jiwa mencapai $13 \%$ dari penyakit secara keseluruhan dan diperkirakan akan berkembang menjadi 25\% di tahun 2030 (WHO, 2009).

Berdasarkan laporan profil kesehatan di Provinsi Nanggro Aceh Darussalam (2008), diketahui masyarakat yang terindikasi gangguan jiwa sebanyak 1.677 jiwa $(31,12 \%)$ termasuk kategori berat, 1.591 jiwa $(29,52 \%)$ mengalami gangguan neurotik dan 1.190 jiwa (22,98\%) mengalami psikotik akut, dan 334 jiwa (6.20\%) mengalami depresi.

Umur puncak untuk skizoprenia pada laki-laki antara 15-25 tahun, sedangkan pada wanita 25-35 tahun. Sebelum umur 10 tahun dan sesudah umur 50 tahun penderita skizoprenia jarang terjadi namun tetap ada. Lebih kurang 90\% pasien skizoprenia yang dirawat dalam rumah sakit jiwa adalah berumur 15-55 tahun dan dapat dikelompkkan secara umum bahwa umur dewasa yaitu antara 26-35 tahun dan 36-45 tahun (Depkes RI, 2009).

Kekambuhan yang dialami pasien disebabkan ketidak patuhan pasien yang mengalami pengobatan. Untuk itu, perlu adanya dukungan dari keluarga, orangorang terdekat dan juga lingkungan sekitar. Melalui pengawasan secara intensif ke pada penderita skizoprenia, maka kepatuhannya untuk selalu mengkonsumsi obat lebih baik, sehingga pasien merasa memiliki tambahan kekuatan dari keluarga dan orang terdekatnya (Nurjanah, 2004).

\section{B. Tujuan Penelitian}

Penelitian ini bertujuan untuk mengetahui hubungan dukungan keluarga dengan kepatuhan minum obat pada pasien skizoprenia di poliklinik RSJ Prof.Dr.Muhammad Ildrem Medan 2018.

\section{Metode Penelitian}

Jenis penelitian ini bersifat analitik dengan pendekatan cross sectional untuk mengetahui hubungan dukungan keluarga dalam kepatuhan minum obat pada pasien skizoprenia. Penelitian ini dilaksanakan di RS Jiwa Prof.Dr.M Ildrem Medan pada bulan Agustus - Nopember 2018

Populasi dalam penelitian ini adalah keluarga pasien skizoprenia yang membawa berobat jalan keluarganya yang menderita skizofrenia di poliklinik RS Jiwa sebanyak 1470 orang, dan besar sampel dalam penelitian ini ditentukan dengan menggunakan rumus Nursalam (2010)

$$
\begin{aligned}
& \mathrm{n}=\frac{\mathrm{N}}{1+\mathrm{N}\left(\mathrm{d}^{2}\right)} \\
& \mathrm{n}=\frac{\mathrm{N}}{\mathrm{N}+1\left(\mathrm{~d}^{2}\right)} \\
& \mathrm{N}=\frac{1470}{1+1470(0,152)} \\
& \mathrm{N}=\frac{1470}{1+1470(0,0225)} \\
& \mathrm{N}=\frac{1470}{22,075}
\end{aligned}
$$

$\mathrm{N}=66,5$ digenapkan 66

Berdasarkan hasil perhitungan maka besar sampel sebanyak 66 responden, agar karakteristik sampel tidak menyimpang dari populasi maka sebelum dilakukan pengambilan data perlu di tentukan kriteria inklusi yaitu keluarga yang membawa pasien skizoprenia berobat di poliklinik RSJ, bersedia menjadi responden, usia 17-65 tahun

Kuesioner dalam penelitian ini berjumlah 30 tentang dukungan keluarga dan kepatuhan minum obat, untuk setiap variabel ada sebanyak 5 kuesioner dengan menggunakan metode skala guttman, jika menjawab (Ya) maka nilai 1 , jika menjawab tidak nilai 0 , yaitu:

1. Instrumental

a. Dukungan baik (jika skor jawaban benar $\geq 50 \%$ )

b. Dukungan kurang (jika jawaban benar $<50 \%$ )

2. Informasional

a. Dukungan baik (jika skor jawaban benar $\geq 50 \%$ )

b. Dukungan kurang (jika jawaban benar $<50 \%$ )

3. Penilaian

a. Dukungan baik (jika skor jawaban benar $\geq 50 \%$ )

b. Dukungan kurang (jika jawaban benar < 50\%)

4. Emosional

a. Dukungan baik (jika skor jawaban benar $\geq 50 \%$ )

b. Dukungan kurang (jika jawaban benar $<50 \%$ )

5. Untuk mengetahui kepatuhan pasien dalam minum obat maka ada 10 pertanyaan yang diajukan kepada responden 


\section{Pengolahan dan Analisa Data}

Setelah data terkumpul dilakukan Analisa Data

1. Analisa Data

Data kemudian dianalisa dengan menggunakan analisa Univariat dan Bivariate . terhadap dua variabel yang diduga berhubungan atau berkolerasi. Misalnya hubungan antara variabel independen dengan variabel dependen. Uji statistik yang digunakan untuk menganalisa hubungan antara setiap variabel independen (dukungan keluarga) terhadap variabel dependen (tingkat kepatuhan) dalam penelitian ini menggunakan uji chi-squer karena skala variabel independen dan variabel dependen merupakan skala katagorik, dengan rumus yang digunakan:

$$
\mathrm{X}^{2}=\frac{\sum(0 \mathrm{i}-\mathrm{Ei})}{\mathrm{E}}
$$

Keterangan :

$$
\begin{aligned}
& \mathrm{X}^{2} \text { : chi-squer } \\
& \sum \text { :jumlah } \\
& \mathrm{O} \text { :nilai observasi dari setiap sel } \\
& \mathrm{Ei} \text { : nilai yang diharapkan }
\end{aligned}
$$

Ketentuan hubungan dikatakan bermakna bila $p$ value $<0.05$ maka Ha diterima berarti ada hubungan signifikan antara kedua variabel yang diteliti

\section{E. Hasil Penelitian}

Dari penelitian yang dilakukan mengenai Hubungan Dukungan Keluarga dengan Kepatuhan minum obat Pada Pasien Skizoprenia di Poliklinik RS Jiwa Prof. Dr. Muhammad Ildrem 2018 kepada 66 responden yang meliputi dukungan emosional, instrumental, informasi, dan penghargaan. Maka diperoleh data yang kemudian diolah dan dianalisa serta disajikan dalam bentuk tabel distribusi seperti di bawah ini.

\section{Analisa Univariat}

Analisa univariat dilakukan menggunakan analisa distribusi, frekuensi, dan statistik deskritif pasien skizoprenia. Dengan tujuan untuk mendapatkan gambaran tentang sebaran (distribusi frekuensi) dari masing-masing karakteristik variabel.

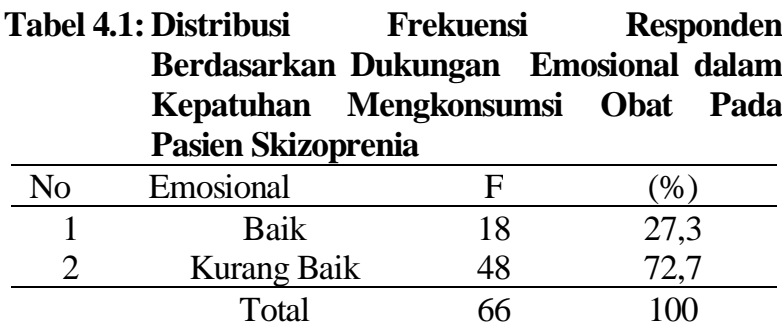

Berdasarkan Tabel 4.1 dapat dilihat bahwa dukungan emosional keluarga yang baik sebanyak 18 responden $(27,3 \%)$
Tabel 4.2 :Distribusi Frekuensi Responden Berdasarkan Dukungan Instrumental dalam Kepatuhan Mengkonsumsi Obat Pada Pasien Skizoprenia

\begin{tabular}{cccc}
\hline No & Instrumental & F & $(\%)$ \\
\hline 1 & Baik & 8 & 11,4 \\
2 & Kurang Baik & 58 & 88,6 \\
\hline & Total & 66 & 100 \\
\hline
\end{tabular}

Berdasarkan Tabel 4.2 dapat dilihat bahwa dukungan instrumental keluarga yang baik sebanyak 8 responden $(11,4 \%)$.

\begin{tabular}{cccc} 
Tabel 4.3 :Distribusi & $\begin{array}{c}\text { Frekuensi } \\
\text { Berdasarkan } \\
\text { dalam Kepatuhan minum } \\
\text { Skizoprenia }\end{array}$ & $\begin{array}{r}\text { Responden } \\
\text { Dukungan }\end{array}$ \\
$\begin{array}{cccc}\text { Informasional } \\
\text { Obada Pasien }\end{array}$ \\
\hline No & Informasional & F & $(\%)$ \\
\hline 1 & Baik & 26 & 39 \\
2 & Kurang Baik & 40 & 61 \\
\hline & Total & 66 & 100 \\
\hline
\end{tabular}

Berdasarkan Tabel 4.3 dapat dilihat bahwa dukungan informasi keluarga yang baik sebanyak 26 responden $(39 \%)$.

\begin{tabular}{cccc} 
Tabel 4.4 :Distribusi & $\begin{array}{c}\text { Frekuensi } \\
\text { Berdasarkan } \\
\text { dalam Kepatuhan minum } \\
\text { Skizoprenia }\end{array}$ & $\begin{array}{r}\text { Responden } \\
\text { Penghargaan }\end{array}$ \\
\hline No & Penghargaan & F & $(\%)$ \\
\hline 1 & Baik & 15 & 22,7 \\
2 & Kurang Baik & 51 & 77,3 \\
\hline & Total & 66 & 100 \\
\hline
\end{tabular}

Berdasarkan Tabel 4.4 dapat dilihat bahwa dukungan penghargaan dari keluarga yang baik sebanyak 15 responden $(23 \%)$.

\begin{tabular}{cccc} 
Tabel 4.5 :Distribusi & $\begin{array}{c}\text { Frekuensi } \\
\text { Berdasarkan Kepatuhan } \\
\text { Pasien Skizoprenia }\end{array}$ & $\begin{array}{c}\text { Responden } \\
\text { minum Obat Pada }\end{array}$ \\
\hline No & Kepatuhan & F & $(\%)$ \\
\hline 1 & Patuh & 36 & 54,5 \\
2 & Tidak Patuh & 30 & 45,5 \\
\hline & Total & 66 & 100 \\
\hline
\end{tabular}

Berdasarkan Tabel 4.5 dapat dilihat bahwa yang patuh minum obat sebanyak 36 responden $(54,5 \%)$.

\section{Analisa Bivariat}

Analisa Bivariat yaitu analisa yang dilakukan untuk mengetahui hubungan dukungan keluarga terhadap tingkat kepatuhan mengkonsumsi obat pada pasien skizoprenia. 
Tabel 4.6 :Hubungan Dukungan Emosional Keluarga dengan Kepatuhan minum Obat Pada Pasien Skizofrenia

\begin{tabular}{|c|c|c|c|c|c|c|c|c|}
\hline \multirow{3}{*}{ No } & \multirow{3}{*}{ Emosional } & \multicolumn{4}{|c|}{ Tingkat Kepatuhan } & & & \multirow{3}{*}{$p$ Value } \\
\hline & & \multicolumn{2}{|c|}{ Patuh } & \multicolumn{2}{|c|}{$\begin{array}{l}\text { Tidak } \\
\text { Patuh }\end{array}$} & \multicolumn{2}{|c|}{ Total } & \\
\hline & & $\mathrm{N}$ & $\%$ & $\mathrm{~N}$ & $\%$ & $\mathrm{~N}$ & $\%$ & \\
\hline 1 & Baik & 5 & 7 & 13 & 20 & 18 & 27 & 0,01 \\
\hline \multirow[t]{2}{*}{2} & $\begin{array}{c}\text { Kurang } \\
\text { Baik }\end{array}$ & 31 & 48 & 17 & 25 & 48 & 73 & \\
\hline & Total & 36 & 55 & 30 & 45 & 66 & 100 & \\
\hline
\end{tabular}

Berdasarkan Tabel 4.6 dapat dilihat bahwa dari 66 responden, yang baik menerapkan dukungan emosional dalam keluarga sebanyak 18 responden, yang patuh sebanyak 5 responden (7\%), dan yang tidak patuh sebanyak 13 responden $(20 \%)$.

Tabel 4.7: Hubungan Dukungan instrumental Keluarga dengan Kepatuhan minum Obat Pada Pasien Skizofrenia

\begin{tabular}{|c|c|c|c|c|c|c|c|c|}
\hline \multirow{4}{*}{ No } & \multirow{4}{*}{$\begin{array}{l}\text { Instrument } \\
\text { al }\end{array}$} & \multicolumn{4}{|c|}{$\begin{array}{r}\text { Tingkat } \\
\text { Kepatuhan }\end{array}$} & & & \multirow{4}{*}{$\begin{array}{c}p \\
\text { Value }\end{array}$} \\
\hline & & \multirow{2}{*}{\multicolumn{2}{|c|}{ Patuh }} & \multirow{2}{*}{\multicolumn{2}{|c|}{$\begin{array}{l}\text { Tidak } \\
\text { Patuh } \\
\end{array}$}} & \multirow{2}{*}{\multicolumn{2}{|c|}{ Total }} & \\
\hline & & & & & & & & \\
\hline & & $\mathrm{N}$ & $\%$ & $\mathrm{~N}$ & $\%$ & $\mathrm{~N}$ & $\%$ & \\
\hline 1 & Baik & 2 & 2,27 & 6 & 9,0 & 8 & 11 & 0,01 \\
\hline \multirow[t]{2}{*}{2} & $\begin{array}{c}\text { Kurang } \\
\text { Baik }\end{array}$ & 34 & 52 & 24 & 36,36 & 58 & 89 & \\
\hline & Total & 36 & 54,27 & 30 & 45 & 66 & 100 & \\
\hline
\end{tabular}

Berdasarkan Tabel 4.7 dapat dilihat bahwa dari 66 responden, menerapkan dukungan Instrumental dari Keluarga, yang baik sebanyak 8 responden, yang patuh 2 responden $(2,27 \%)$, dan yang tidak patuh sebanyak 6 responden $(9,0 \%)$.

Tabel 4.8: Hubungan Dukungan Informasi Keluaraga dengan Kepatuhan minum Obat Pada Pasien Skizoprenia

\begin{tabular}{|c|c|c|c|c|c|c|c|c|}
\hline \multirow[t]{3}{*}{ No } & \multirow[t]{3}{*}{ Informasi } & \multicolumn{4}{|c|}{$\begin{array}{c}\text { Kejadian } \\
\text { Skizofrenia }\end{array}$} & & & \multirow{3}{*}{$\begin{array}{c}p \\
\text { Value }\end{array}$} \\
\hline & & \multicolumn{2}{|c|}{ Patuh } & \multicolumn{2}{|c|}{$\begin{array}{l}\text { Tidak } \\
\text { Patuh }\end{array}$} & \multicolumn{2}{|c|}{ Total } & \\
\hline & & $\mathrm{N}$ & $\%$ & $\mathrm{~N}$ & $\%$ & $\mathrm{~N}$ & $\%$ & \\
\hline 1 & Baik & 15 & 23 & 10 & 16 & 25 & 39 & 0,05 \\
\hline 2 & $\begin{array}{c}\text { Kurang } \\
\text { Baik }\end{array}$ & 21 & 32 & 20 & 29 & 41 & 61 & \\
\hline & Total & 36 & 55 & 30 & 45 & 66 & 100 & \\
\hline
\end{tabular}

Berdasarkan Tabel 4.8 dapat dilihat bahwa dari 66 responden, yang baik menerapkan dukungan keluarga informasi sebanyak 25 responden, yang patuh sebanyak 15 responden (23\%), dan yang tidak tidak patuh sebanyak 10 responden $(16 \%)$.
Tabel 4.9: Hubungan Dukungan penghargaan Keluarga dengan Kepatuhan minum Obat Pada Pasien Skizofrenia

\begin{tabular}{|c|c|c|c|c|c|c|c|c|}
\hline \multirow{3}{*}{ No } & & \multicolumn{4}{|c|}{ Tingkat Kepatuhan } & & & \multirow{3}{*}{$\begin{array}{c}p \\
\text { Value }\end{array}$} \\
\hline & \multirow[t]{2}{*}{$\begin{array}{c}\text { Pengharg } \\
\text { aan }\end{array}$} & \multicolumn{2}{|c|}{ Patuh } & \multicolumn{2}{|c|}{$\begin{array}{l}\text { Tidak } \\
\text { Patuh }\end{array}$} & \multicolumn{2}{|c|}{ Total } & \\
\hline & & $\mathrm{N}$ & $\%$ & $\mathrm{~N}$ & $\%$ & $\mathrm{~N}$ & $\%$ & \\
\hline 1 & Baik & 10 & 22 & 0 & 0 & 10 & 23 & 0,00 \\
\hline 2 & $\begin{array}{l}\text { Kurang } \\
\text { Baik }\end{array}$ & 14 & 32 & 20 & 45 & 34 & 77 & \\
\hline & Total & 24 & 54 & 20 & 45 & 44 & 100 & \\
\hline
\end{tabular}

Berdasarkan Tabel 4.9 dapat dilihat bahwa dari 66 responden, yang baik menerapkan dukungan keluarga penghargaan sebanyak 10 responden (22\%), dan semuanya patuh.

\section{F. Pembahasan}

1. Hubungan dukungan emosional keluarga dalam kepatuhan minum obat pada pasien skizoprenia menunjukkan bahwa Hasil penelitian ini dapat diasumsikan ada hubungan dukungan emosional dalam kepatuhan mengkonsumsi obat pada pasien skiziprenia. Bahwa dukungan emosional dari keluarga yang diterapkan oleh 18 responden, yang patuh 5 responden (7\%) dan tidak patuh sebanyak 13 responden $(20 \%)$, sedangkan 18 responden menerapkan dukungan keluarga emosional yang baik. Dengan perolehan pada analisa bivariate $p$ value $=0,01$ dengan $p<0,05 \mathrm{Ha}$ diterima artinya penelitian yang dilakukan signifikan antara dukungan emosional keluarga dalam kepatuhan minum obat pada pasien skizofrenia..

Hasil ini sejalan dengan teori Simatupang (2005) terletak pada metode penelitian yang digunakan peneliti menggunakan sampel sebanyak 30 responden menggunakan accidental sampling sehingga dengan sampel ini lebih bervariasi, akurat dan merata. Hal ini karena peningkatan dukungan keluarga emosional diperoleh melalui penghargaan yang diberikan kepada pasien yang akan menambah kepatuhan pada pasien. Maka dapat diasumsikan hasil penelitian dukungan emosional yang berhubungan baik karena keluarga selalu meluangkan waktu untuk mendengarkan apa yang sedang dirasakan pasien, keluarga menyadari bahwa pasien sangat membutuhkan dukungan keluarga dengan penuh kasih sayang selayaknya orang normal.

Adanya hubungan dukungan keluarga emosional terhadap tingkat kepatuhan mengkonsumsi obat pada pasien skizoprenia

Dari hasil uji statistik pada dukungan emosional diperoleh nilai $\mathrm{p}=0,01(\mathrm{p}<\alpha=0,05)$ yang artinya $\mathrm{Ha}$ diterima ada hubungan antara dukungan emosional dengan kepatuhan minum obat pada pasien skizofrenia. Karena wujud kasih sayang (emosional) yang diberikan keluarga kepada salah satu anggota keluarga yang menderita suatu penyakit sangat memengaruhi penyembuhan pasien (Friedman, 1998). Dukungan emosional yang diberikan kepada pasien akan mendorong pasien untuk menjalani pengobatan secara teratur, hal ini dikarenakan dukungan 
yang diberikan tersebut dijadikan sebagai energi penggerak bagi pasien dalam menjalankan suatu program terapi (Sudirman, 2001).

2. Hubungan dukungan keluarga instrumental terhadap tingkat kepatuhan mengkonsumsi obat pada pasien skizoprenia

Dari tabel hubungan dukungan keluarga keluarga terhadap tingkat kepatuhan mengkonsumsi obat pada pasien skizoprenia menunjukkan bahwa 8 responden menerapkan dukungan keluarga instrumental yang baik. Yang patuh 2 responden, dan yang tidak patuh sebanyak 6 responden. Dengan perolehan pada analisa bivariate $p$ value $=0,01$ dengan $\mathrm{p}<0,05$ artinya ada hubungan antara dukungan instrumental dalam kepatuhan minum obat pada pasien skizoprenia. Dari hasil penelitian ini dapat diasumsikan hubungan dukungan instrumental keluarga ada berhubungan dalam kepatuhan minum obat.

Hubungan Dukungan Informasi dari keluarga Terhadap Tingkat Kepatuhan minum Obat Pada Pasien Skizoprenia

Dari tabel hubungan dukungan keluarga terhadap tingkat kepatuhan minum obat pada pasien skizofrenia menunjukkan bahwa 25 responden menerapkan dukungan informasi keluarga yang baik. Yang patuh sebanyak 15 responden, dan yang tidak patuh sebanyak 10 responden. Dengan perolehan pada analisa bivariate $p$ value $=0,005$ dengan $\mathrm{p}<0,05$ artinya ada hubungan antara dukungan keluarga dalam kepatuhan minum obat pada pasien skizoprenia.

Dari hasil penelitian ini terdapat hubungan dukungan informasi dalam kepatuhan minum obat pada pasien skizofrenia. Bahwa dukungan informasi keluarga yang baik 25 responden, yang patuh 15 responden $(23 \%)$ dan yang tidak patuh sebanyak 10 responden $(16 \%)$.

Hasil penelitian ini sejalan dengan penelitian yang dilakukan Ermina (2010) yang menyebutkan bahwa keluarga memberikan dukungan yang adekuat yang terus menerus selama pasien dirawat baik dukungan penghargaan yang nyata, yaitu dukungan informasi.

3. Hubungan Dukungan Penghargaan dari keluarga Terhadap Tingkat Kepatuhan minum Obat Pada Pasien Skizofrenia

Dari tabel hubungan dukungan keluarga terhadap tingkat kepatuhan mengkonsumsi obat pada pasien skizofrenia menunjukkan bahwa 10 responden, menerapkan dukungan keluarga penghargaan yang baik dan semuanya patuh mengonsumsi obat

Hasil penelitian ini sejalan dengan penelitian yang dilakukan oleh Dwi Oktavianus (2010), mengenai hubungan dukungan keluarga dengan kepatuhan minum obat diwilayah kerja puskesmas karang anyar gandusari trenggalek. Dari hasil data dengan menggunakan uji statistik chi squer pada $\alpha=0,05$ didapatkan hasil data dengan nilai signifikan 0,024 berarti ada hubungan pengaruh antara peran keluarga dengan kepatuhan minum obat pada pasien skizoprenia di wilayah kerja puskesmas karanganyar gandusari trenggalek. Maka dapat diasumsikan hasil penelitian dukungan penghargaan yang baik karena keluarga selalu memberi penguatan yang positif agar pasien tidak ,merasa dianggap gila dan perlu perhatian selayak nya orang normal pada umumnya. Karena keluarga memberikan kritikan yang bersifat membangun dan menghargai usaha yang dilakukan pasien. Sehingga pasien termotivasi untuk lebih meningkatkan kesehatannya. Seperti yang diungkapkan Siagia dalam Koiser (2004) ketika seseorang mendapat pujian atau dorongan positif dari orang lain, maka orang tersebut cenderung mengulangi tindakan yang sama.

4. Hubungan dukungan keluarga informasi terhadap tingkat kepatuhan mengkonsumsi obat pada pasien skizoprenia

Pada dukungan informasi diperoleh uji statistik chi square nilai $\mathrm{p}=0,65(\mathrm{p}<\alpha=0,05)$ yang artinya Ha ditolak yang artinya tidak ada hubungan antara dukungan informasi dengan tingkat kepatuhan mengonsumsi obat pada pasien skizoprenia. Dan pada dukungan penghargaan diperolah hasil statistik chi square nilai $\mathrm{p}=0,00(\mathrm{p}<\alpha=0,05)$ yang artinya $\mathrm{Ha}$ diterima ada hubungan antara dukungan penghargaan terhadap tingkat kepatuhan mengonsumsi obat pada pasien skizoprenia. Dari 17 responden yang patuh mengonsumsi obat sebanyak 10 responden, dan yang tidak patuh sebanyak 7 responden. Karena keluarga hanya berbicara tanpa memperhatikan pasien mengkonsumsi obat. Dan kurangnya pengetahuan tentang penyakit yang dialami pasien karena keluarga menganggap itu hal yang memalukan jika diketahui masyarakat.

Telah dibuktikan bahwa pada masing-masing dukungan keluarga ada perbedaan proporsi dengan tingkat kepatuhan mengonsumsi obat pada pasien skizoprenia, antara dukungan emosional, instrumental, informasi, dan penghargaan. Ha diterima yaitu yaitu terdapat hubungan yang signifikan pada dukungan emosional dan penghargaan, dan ha ditolak pada dukungan instrumental dan informasi demokratis dengan tingkat kepatuhan mengonsumsi obat pada pasien skizofrenia di Poliklinik Rumah Sakit Jiwa Prof. Dr. Muhammad Ildrem Medan Sumatra Utara.

\section{A. Kesimpulan}

Dari hasil penelitian yang dilakukan mengenai “ Hubungan Dukungan Keluarga Terhadap Tingkat Kepatuhan Mengkonsumsi Obat Pada Pasien Skizoprenia di Poliklinik Rumah Sakit Jiwa Prof. Dr. Muhammad Ildrem Medan Tahun 2018”. Dapat saya simpulkan bahwa:

1. Adanya hubungan dukungan Emosional keluarga dalam Kepatuhan dalam Obat Pada Pasien skizoprenia di Poliklinik RS Jiwa Prof. Dr. M.Ildrem Medan 2018. Dari 12 responden memberi dukungan emosional dengan baik, yang patuh minum obat sebanyak 9 responden, dan yang tidak patuh menkonsumsi obat sebanyak 3 responden.

2. Adanya hubungan dukungan instrumental keluarga dalam Kepatuhan minum Obat Pada Pasien 
skizoprenia di poli klinik RS Jiwa Prof. Dr. M.Ildrem Medan 2018.

3. Adanya hubungan dukungan informasi keluarga dalam kepatuhan minum obat pada pasien skizoprenia di Poliklinik RS Jiwa Prof. Dr. M. Ildrem Medan 2018. Dari 17 responden yang yang patuh mengkonsumsi obat sebanyak 10 responden, dan yang tidak patuh sebanyak 7 responden.

4. Adanya hubungan dukungan penghargaan keluarga dalam kepatuhan minum obat pada pasien skizoprenia di poliklinik Rumah Sakit Jiwa Prof. Dr. M.Ildrem Medan 2018. Ada 10 responden memberi dukungan penghargaan dengan baik, dan semua patuh minum obat.

\section{Saran}

Disarankan bagi perawat agar mengembangkan teori keperawatan jiwa dan dapat memberikan masukan kepada keluarga pasien tentang pentingnya dukungan keluarga dalam kewsembuhan pasien dan kepatuhan, anjuaran keluarga dalam pengawasan minum obat pada pasien skizoprenia.

\section{Daftar Pustaka}

Arif S. A.2006 Skizoprenia memahami dinamika keluarga pasien. Cetakan I. Bandung: Revina Aditama.

Becker, et al. 2001. Keyakinan,sikap dan kepribadian Diakses melalui http://.jurnal.unimus.ac.id/index.php/jkj/artichel/v iew/980/1029

Depkes RI. 2009. Riset Kesehatan Dasar. Jakarta : Badan Penelitian dan Pengembanagn Kesehatan Republik Indonesia.

Friedman, 1998. Keluarga Teori dan Praktek. Jakarta: EGC

Hawari . 2001. Pendekatan Holistik Pada Gangguan Skizoprenia. FK UI. Jakarta. 2001.Skizoprenia. Gaya Baru. Jakarta

Maramis, W. F., 2004. Catatan Ilmu Kedokteran Jiwa. Edisi 9. Surabaya : Airlangga Universitas press.
Nasir, A \& Muhith, A. 2011. Dasar-Dasar Keperawatan Jiwa. Jakarta : Salemba Medika.

Niven, Neil. 2002. Psikologi Kesehatan.Cetakan I. Jakarta:EGC

Nurjanah. 2001. Psikologi Perkembangan untuk Keperawatan. Penerbit BukuKedokteran. EGC: Jakarta.

Potter \& Perry, 2006, Fundamental Keperawatan Konsep, Proses danPraktek Edisi 4, EGC, Jakarata : 612 633

Rudyanto, Benhard. 2007. Skizoprenia Dan Diagnosa Banding. Jakarta: FKUI

Setiadi, 2008, Konsep dan Proses Keperawatan Keluarga, Graha Ilmu,Yogyakarta : $1-21$

Stuart and Laria. 1998. Ketidak Patuhan Minum Obat. Diakses

melaluihttp://www.jurnal.unimus.ac.id/index.php/ $\mathrm{jkj} / \mathrm{view} / 909 / 963$

Taylor. 2006. Dukungan Keluarga. Diakses melalauihttp://jurnal.unimus.ac.id/index.php/jk $\mathrm{j} /$ article/view/980/1029

WHO. $2001 \quad$ Schizoprenia. Diakses melalui http://www.who.int/mentalhealt/topic,html

-2007. Schizoprenia. Diakses melalui http://www.who.int/mentalhealt/topic,html

2009. Schizoprenia. Diakses melalui http://www.who.int/mentalhealt/topic,html

Waspadji, S, 2007, Penatalaksanaan Jiwa, Fakultas Kedokteran Universitas Indonesia, Jakarta

Yosep,. 2009. Keperawatan Jiwa. PT. Refika Aditama. Bandung. 